\title{
Correction notice to: Experimental in-situ metallographic investigations of industrial hydrocarbon processed fired heater tubes
}

\section{Metall. Res. Technol. 116, 203 (2019), https://doi.org/10.1051/metal/2018062}

Chidambaram Subramanian ${ }^{*}$

Numaligarh Refinery Limited (A Group Company of Bharat Petroleum Corporation Limited), Assam, India

Received: 18 September 2019 / Accepted: 24 September 2019

Errors were introduced in the original version of the article published in Metall. Res. Technol. 116, 203 (2019). Following a production error, the article has been entirely republished (see next page). Publisher apologizes for the inconvenience.

Cite this article as: Chidambaram Subramanian, Correction notice to: Experimental in-situ metallographic investigations of industrial hydrocarbon processed fired heater tubes, Metall. Res. Technol. 117, 106 (2020)

\footnotetext{
* e-mail: chidambaramselva@gmail.com
} 


\title{
Experimental in-situ metallographic investigations of industrial hydrocarbon processed fired heater tubes
}

\author{
Chidambaram Subramanian ${ }^{*}$ \\ Numaligarh Refinery Limited (A Group Company of Bharat Petroleum Corporation Limited), Assam, India
}

Received: 19 January 2018 / Accepted: 25 June 2018

\begin{abstract}
In the present investigations, the coker unit heater tube has been evaluated using in-situ metallography, after an exposure at a temperature of $615^{\circ} \mathrm{C}$ for around $52000 \mathrm{~h}$. The heater tubes in petroleum industries are mostly damaged by creep failures; hence metallography assessments are conducted for safe operation of industrial units. The primary material of construction for fired heater tubes is ASTM A213 GrT9 chromium molybdenum ferritic steel and maximum primary creep strains are estimated as $11.2761 \times 10^{-2}$ and $11.2802 \times 10^{-2}$ for temperature 888 and $923 \mathrm{~K}$, respectively. In-situ metallography test was conducted at finish pass surface on one butt weld joint section of two different passes (pass I and pass II) of heater tubes. Hardness is within limit and chemical composition stands confirmed within material standards. A heater tube weld joint comprising weldment metal, heat affected zone and base metal were found in good condition, and no indications of creep were observed. Tempered martensite is observed only in weld metal and heat affected zone which aids in high temperature creep strength of metal at weld joint and heat affected zone. No martensitic structure was observed on the base metal; however base metal creep strength was ascertained by fine precipitated alloy carbides within the ferritic matrix base metal structure. Recommendations were further provided to monitor the performance of heater tubes and for an early prediction of secondary creep.
\end{abstract}

Keywords: coker plant / creep damage / ferritic alloy steels / pressure tubes / metallography

\section{Introduction}

The heater tubes of coker unit made up of ( $\mathrm{Cr}-\mathrm{Mo})$ ferritic steel grades were operated up to $650{ }^{\circ} \mathrm{C}$ as specified by Boiler and Pressure vessel codes (BPV) [1-3]. According to creep constituent equations an increase in temperature decreases the tensile strength of material due to atom mobility [4], grain boundary sliding [5], grain rotation and cavity formation [6] at high temperatures. The metallurgical stability, high temperature mechanical properties and high temperature oxidation of chromium molybdenum steel grades are evaluated in the literature [7] and $650^{\circ} \mathrm{C}$ was shown to be the design limit for aforementioned steel grades [1]. Even though higher operating temperature of heater tube is permitted within design limit, the tubes may rupture after prolonged exposure at such high temperatures [2,8-10]. The heater tubes affected from creep failure may result in sudden release of hydrocarbon fluid (vacuum residue) during heater tube operations which may lead to catastrophic failure of the furnace. However, failure shall be avoided if operated tubes were subjected to intermediate

\footnotetext{
* e-mail: chidambaramselva@gmail.com
}

nondestructive experimental investigations like in-situ metallography, remaining life assessments and stress analysis [10]. All those tests are conducted to predict actual life or remaining life of heater tubes after considering ideal, re-rated and design operational conditions.

The time dependent mechanical behavior at constant stress is called creep [2]. The creep curve plotting time vs. strain in many literatures [5] shows that creep rate decreases during primary creep, approaches a constant creep rate in secondary creep and finally increases in the tertiary creep regime [10]. Applications of creep behavior and its studies on metallic systems are not only limited to oil and gas industries, it also extends to power plants, rocket engines and chemical process industries [4-6,8,11]. Therefore understanding creep behavior of ferritic T9 grade is important for safe operation of coker units in petroleum industries. Many international design codes and standards recommend in-situ metallography to evaluate creep damage for hydrocarbon process fired heater tubes.

Replication in which the topography of micro structural features from the heater tubes are preserved as a negative relief is called as in-situ metallography [12]. Generally negative relief obtained on a plastic film is further studied under light optical microscope or scanning electron 
microscope [12,13]. Entire replication is a duplication process of heater tubes without affecting it and it is called nondestructive testing. However, there may be chances in loss of few micro structural features namely oxides, carbides, sulfides or any other precipitates during replica extraction polishing and etching [13].

\section{Background information}

The material of construction of heater tubes were ASTM A213 GrT9 (refer chemical composition in Tab. 1 and mechanical property in Tab. 2) with dimensions of $\phi 101.6 \times t 11.81 \mathrm{~mm}^{2}$ and corrosion allowance is $3 \mathrm{~mm}$ [1]. During initial phase of construction the single V butt joint was prepared and preheated to $260^{\circ} \mathrm{C}$ prior to welding $[1,2,10]$. After pre-heating, the heater tubes were welded by E8018-B8L welding consumables and weld joints were subjected to radiographic testing. Interpass temperature were also maintained as $260^{\circ} \mathrm{C}$. Weldment complied with para QW191 Section V of ASME BPV code and there was no indication of welding defects from radiographic interpretation. Subsequently the weld joints were subjected to post weld heat treatment (as shown in Fig. 1) at heating and cooling rate of $100^{\circ} \mathrm{C} / \mathrm{hr} /$ in thickness and soaked at $732^{\circ} \mathrm{C}$ for maximum $2 \mathrm{~h}$. The same joints were again subjected to radiographic testing after post weld heat treatment and no significant indications were obtained.

The heater tubes were hydro tested at $70 \mathrm{~kg} / \mathrm{sq} . \mathrm{cm}$ for 60 minutes for pass I and pass II separately and there was no leakage or pressure drop. Radiation zone comprises of 34 heater tubes with two separate passes with each pass having 17 heater tubes as shown in Figure 2. The heater tubes operated with internal pressure at $36.0 \mathrm{~kg} / \mathrm{sq} . \mathrm{cm}$ $(7.59 \mathrm{MPa})$ and $615^{\circ} \mathrm{C}$. All these records were obtained from documentation and reviewed further to confirm structural integrity of industrial hydrocarbon processed fired heater tubes. This industrial furnace tubes have not undergone any turnaround or intermediate plant outrage for a last 52000 operated hours.

\section{Experimental procedures}

The replicas of heater tube weld section were chosen for insitu metallographic assessment from radiation zone inside furnace area as shown in Figure 2 and three dimensional view of industrial coker furnace is shown in Figure 3 [5]. Demagnetization treatment was not necessary prior to replication process as it was pre-confirmed that the heater tubes were not magnetized. Subsequently manual surface cleaning is carried out with an utmost care and then it is ensured that surface is free from scratches; deformation, polishing defects and other artifacts like etch pits during cleaning process $[12,13]$. Otherwise aforementioned defects may obscure original topography of micro structural features. During grinding, decarburization of heater tube surface is evaluated by measuring its hardness value. No significant hardness value is obtained during its measurement [12].
Table 1. Chemical composition of ASTM A213 GrT9 tube.

\begin{tabular}{ll}
\hline Elements & Composition (\%) \\
\hline Carbon & 0.15 max. \\
Manganese & $0.30-0.60$ max. \\
Phosphorous & 0.025 max. \\
Sulfur & 0.025 max. \\
Silicon & $0.25-1.0$ max. \\
Chromium & $8.0-10.0$ \\
Molybdenum & $0.90-1.10$ \\
Iron & $87.1-90.35$ \\
\hline
\end{tabular}

Table 2. Mechanical property of ASTM A213 GrT9 tube.

\begin{tabular}{ll}
\hline Mechanical property & Value \\
\hline Tensile strength & $415 \mathrm{MPa}$ \\
Yield strength & $205 \mathrm{MPa}$ \\
Elongation & 30 Percentage \\
Hardness & $190-217 \mathrm{BHN}$ \\
\hline
\end{tabular}

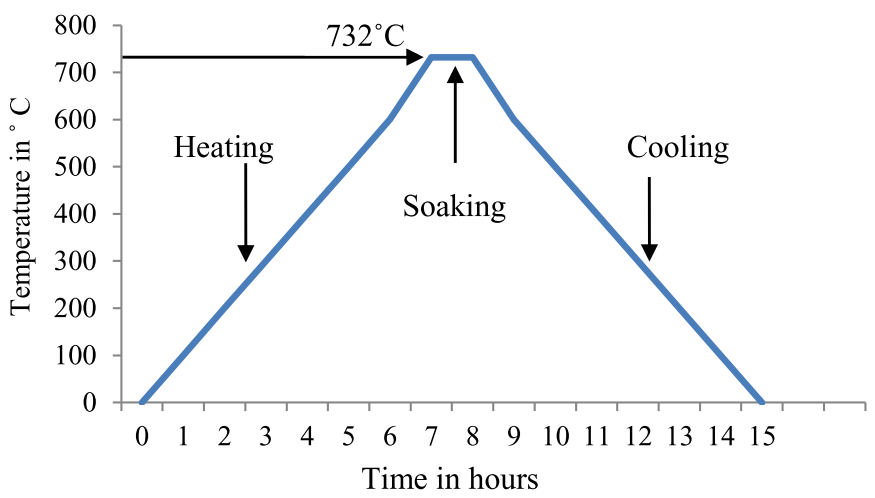

Fig. 1. Post weld heat treatment cycle followed for Grade T9 heater tubes weld joints during furnace construction.

Two replica samples were taken from tube no 1 and 34 representing from pass I and pass II, respectively (refer Fig. 2). As the weld section constitutes of weld fusion zone, heat affected zone and base metal, it is not required to study bare metal separately [10]. Therefore, in the present study the replica was considered from weld section measuring a total length of $26 \mathrm{~mm}$, i.e., symmetrically $13 \mathrm{~mm}$ on both sides from weld centerline of heater tube surface covering weldment, HAZ and base metal [12]. A plastic film sheet is taken and one side was applied with methyl acetate until it is wet and then the wetted side was applied on the prepared heater tube surface [13]. Subsequently the plastic film is pressed firmly on heater tube surface for $25 \mathrm{~s}$ for metal adherence. In replica extraction acetone may also be used as solvent instead of 


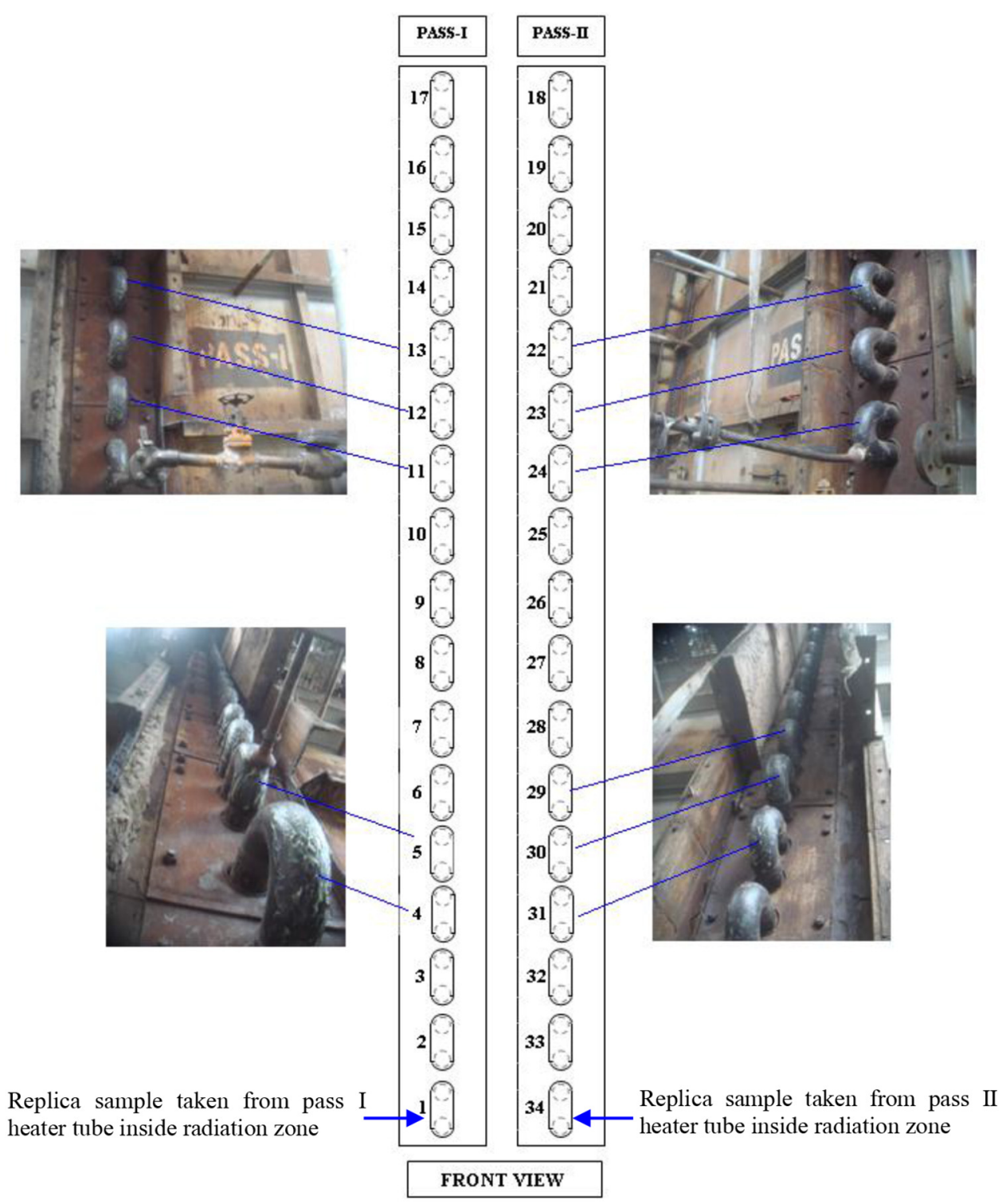

Fig. 2. Schematic view of pass I and pass II front view of hydrocarbon processed heater tubes.

methyl acetate $[12,13]$. On the prepared heater tube, rubber based replicating compound is applied gently. Then it is covered with tube carrier paper and rolled to spread the rubber based compound in thin uniform layer under it.

The replica is removed and mounted on rigid side after drying the film completely. Black ink was applied on back side of replica slide to enhance image contrast and the prepared replica attached with carrier slides is stored permanently. To avoid any contamination, the heater tube was washed thoroughly with de-mineralized water after replica preparation [12]. Utmost care was taken during specimen preparation and post preparation transfer to avoid folding or any contamination or oxidation. The metallography is analyzed by light optical microscope of Zeiss Axio Vert.A1. Diamond pyramid indenter of MIC 201A GE make is used for measuring hardness value and $\mathrm{X}$-ray fluorescence technique (positive material identification) is used for analyzing the chemical composition of heater tubes.

\section{Estimation of creep strain}

The intention is to estimate the creep strain after exposure of $52000 \mathrm{~h}$ at high temperature and heater tubes have experienced neither temperature drop nor internal pressure drop during last 52000 operated hours. For the current steel and the mechanical and thermal conditions, no creep data/creep laws/measurement was available in literatures. Kafexhiu et al. [7] has measured creep properties of steel grades X20 and P91 which are of comparable composition with ASTM T9 grade at $853 \mathrm{~K}$, although the measurements were made with $\sigma=170 \mathrm{MPa}$ and only up to $100 \mathrm{~h}$, and thus for much shorter times. To represent his results, Kafexhiu et al. [7] uses the expression as stated in equation (1) however without revealing the numerical values of the constants $\mathrm{A}$ and $\mathrm{B}$. The temperature dependent material constants, $\mathrm{A}$ and $\mathrm{B}$, are independent of stress while B is unit less, the creep strain hardening coefficient, $\mathrm{A}$, has unit of 


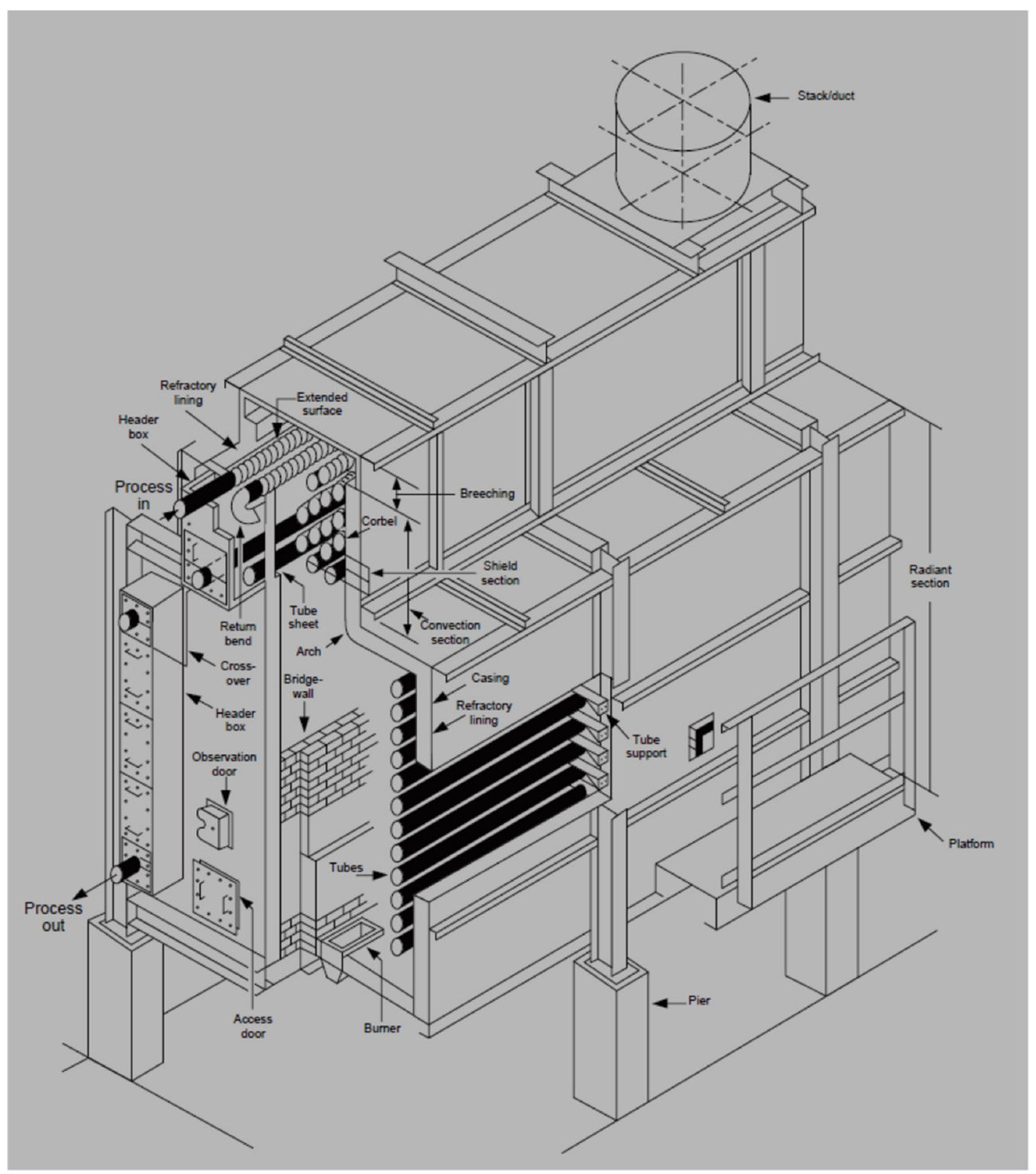

Fig. 3. Industrial coker furnace heater tubes in three dimensional views [5].

$M P a^{-1} h r^{-\left(\frac{B}{K}\right)} \%$ which is consistent with stress, $\sigma$, and time, $t$.

$$
\varepsilon(t)=A \cdot \sigma \cdot t^{B / T}
$$

By curve fitting of Kafexhiu's experimental results to this expression, the coefficients have been re-estimated as $A=1.47 \mathrm{MPa}^{-1} h r^{-\left(\frac{B}{K}\right) \%}$ and $B=0.97$. The resulting expression was numerically evaluated for $\sigma=7.59 \mathrm{MPa}$ at temperatures $T=923$ and $888 \mathrm{~K}$ over a time of $52000 \mathrm{~h}$. The internal stress, $\sigma$, of heater tube is derived from hoop stress as stated in equation (2). An internal pressure of tube is $P=36.00 \mathrm{kgcm}^{-2}$, outer diameter of tube is $D=101.60 \mathrm{~mm}$ and tube thickness is $t=11.81 \mathrm{~mm}$, the hoop or circumferential stress $\sigma$ is calculated as 7.59 MPa.

$$
\sigma=\frac{P D}{4 t}
$$

The creep strain is within primary creep regime obtained from operational creep analysis and maximum creep strain is found $(\varepsilon)=11.2761 \times 10^{-2}$ and $(\varepsilon)=11.2802$ $\times 10^{-2}$ for temperature 888 and $923 \mathrm{~K}$, respectively.

The creep strain estimation cannot be more than a rough approximation and further creep studies are needed. It is inferred from Figure 4 that creep strain rate decreases with increase in total accumulated strain. It is very well known that the rupture life of heater tube material was inversely proportional to minimum creep rate and cavity formation and cavity growth was fundamental mechanism for high temperature heater tube evaluation. 


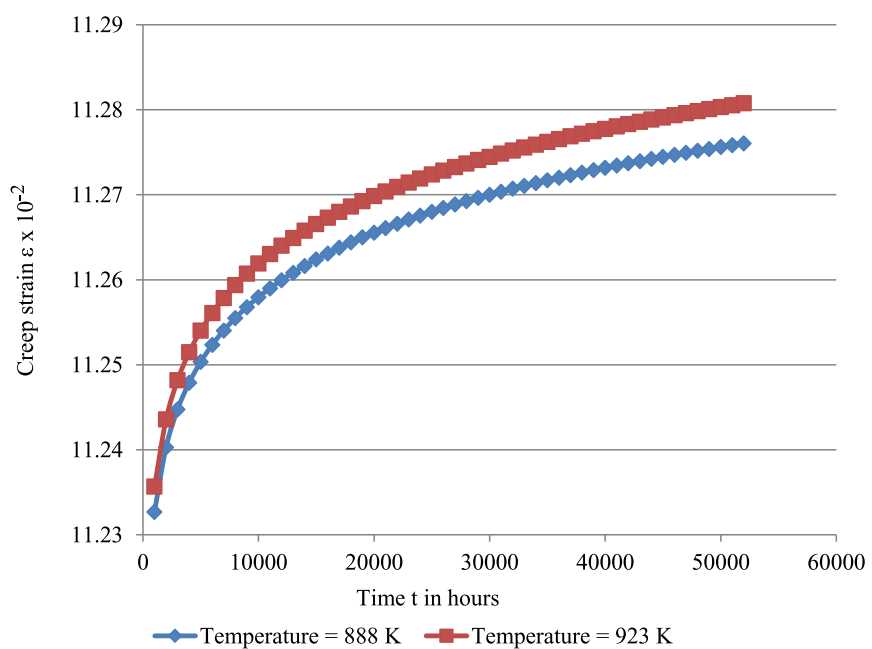

Fig. 4. Primary creep curve of industrial coker furnace heater tubes.
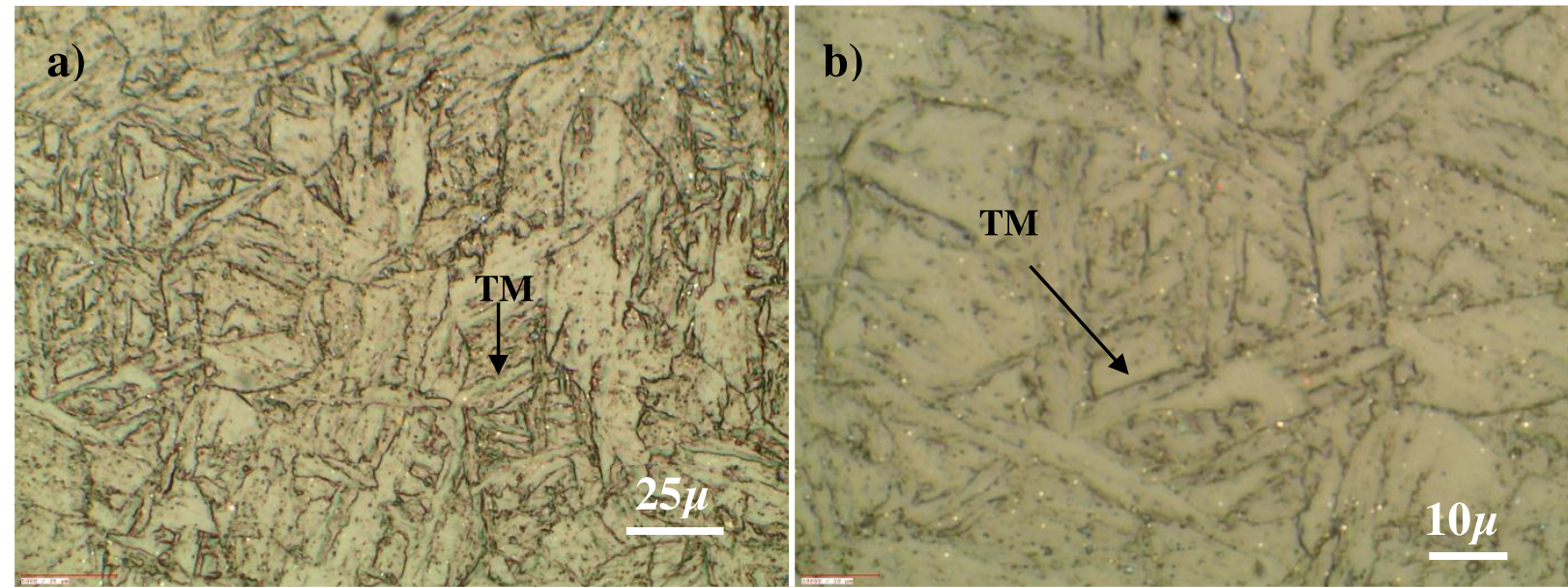

Fig. 5. a: Weld metal area at lower magnification and; b: weld metal area at higher magnification of pass I tube, TM-tempered martensite grain structure.
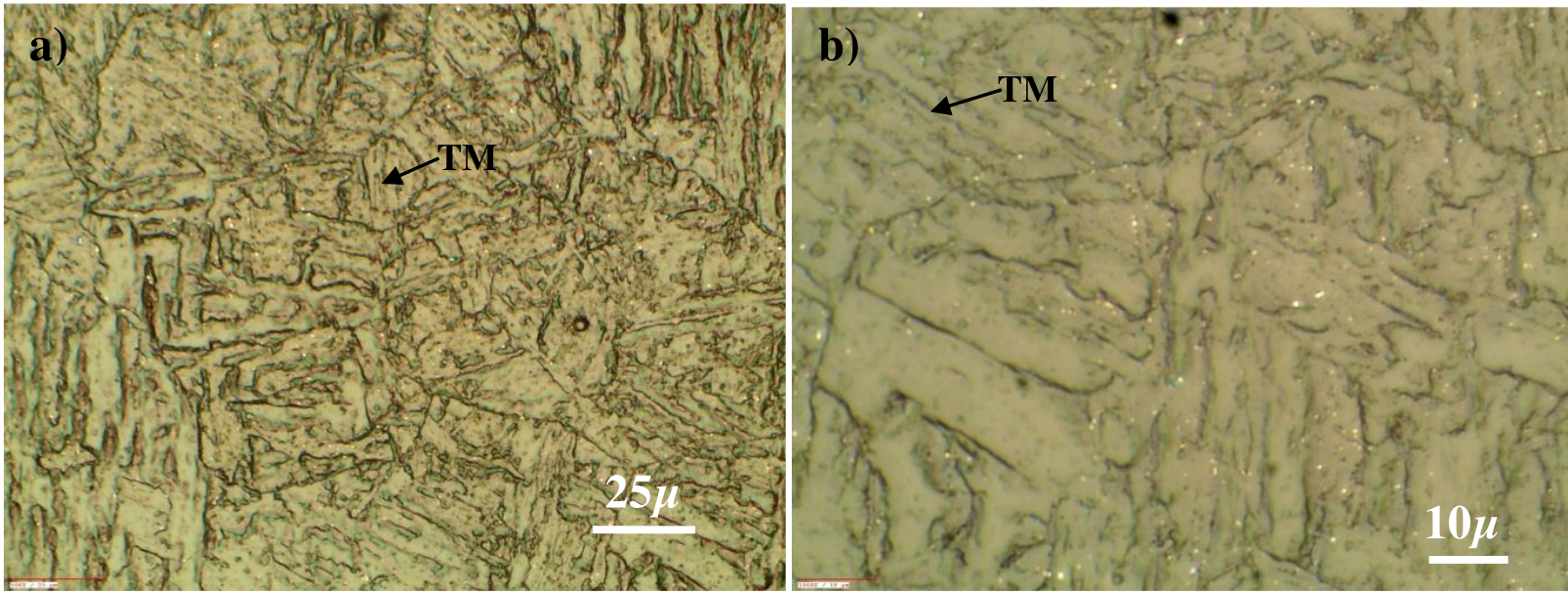

Fig. 6. a: Weld metal area at lower magnification and; b: weld metal area at higher magnification of pass II tube, TM-tempered martensite grain structure. 

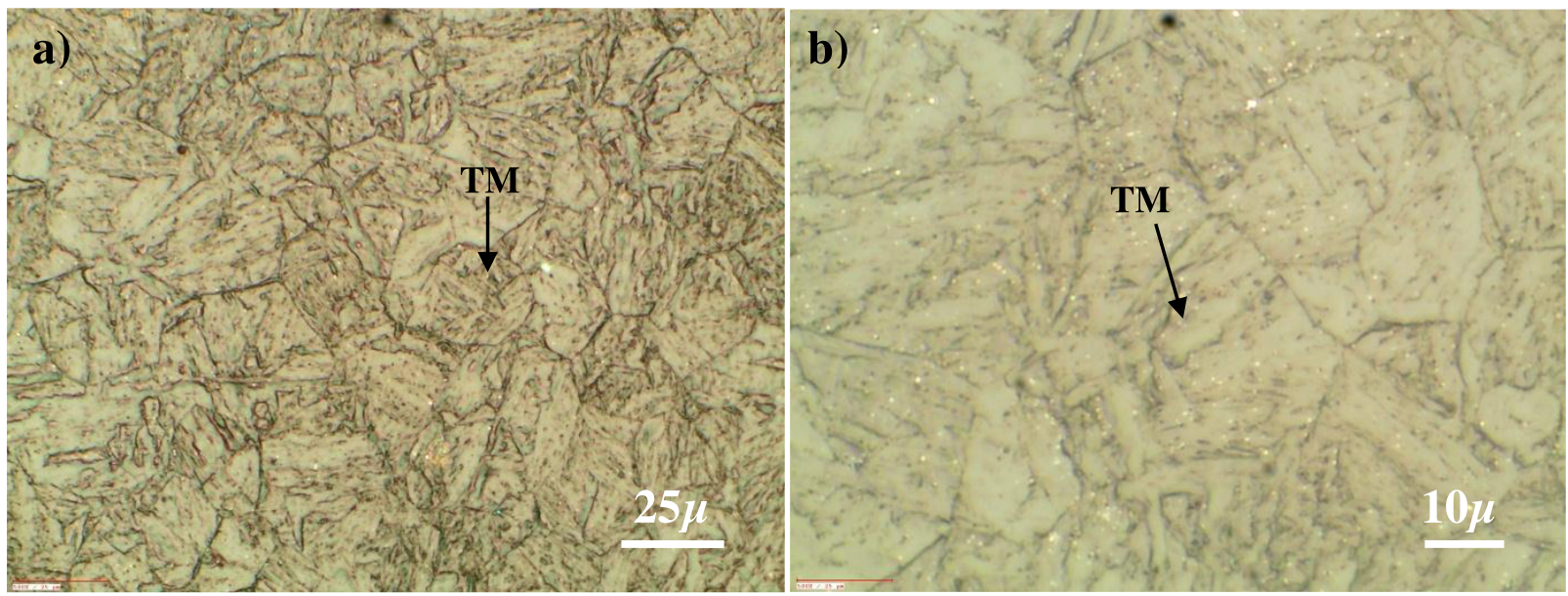

Fig. 7. a: HAZ area at lower magnification and; b: HAZ area at higher magnification of pass I tube, TM-tempered martensite grain structure.

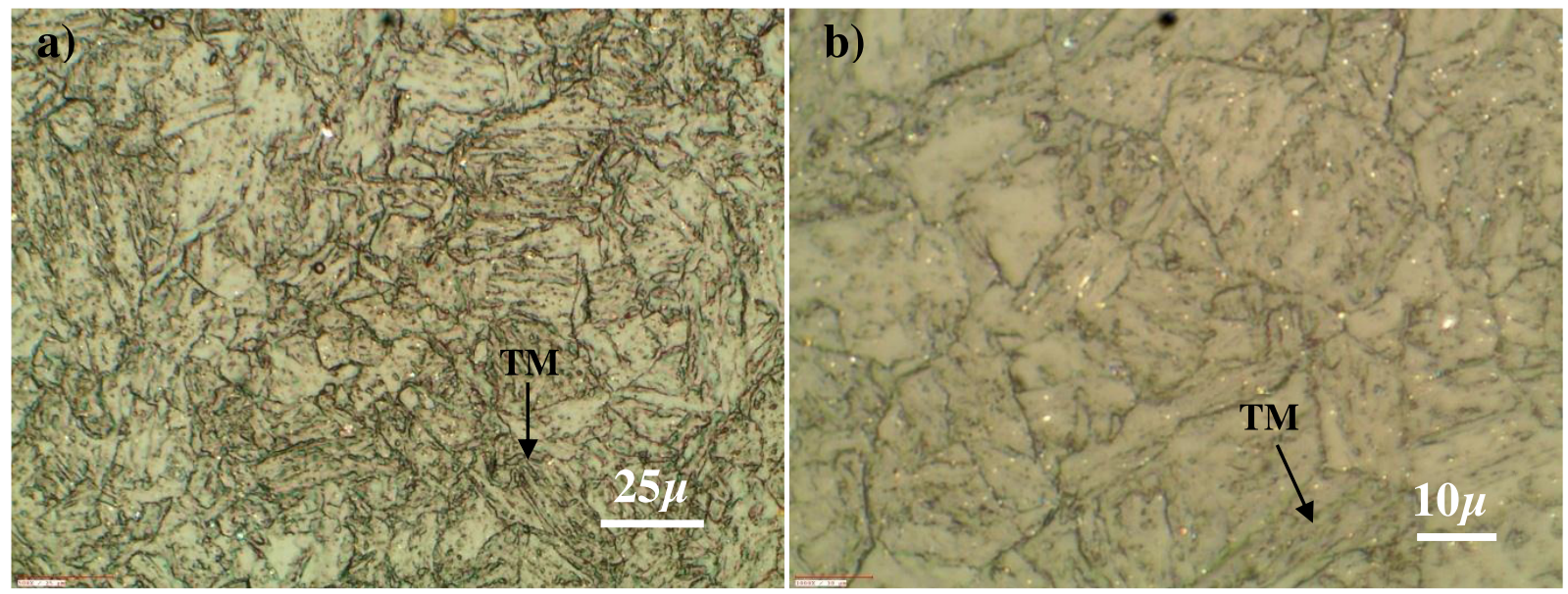

Fig. 8. a: HAZ area at lower magnification and; b: HAZ area at higher magnification of pass II tube, TM-tempered martensite grain structure.
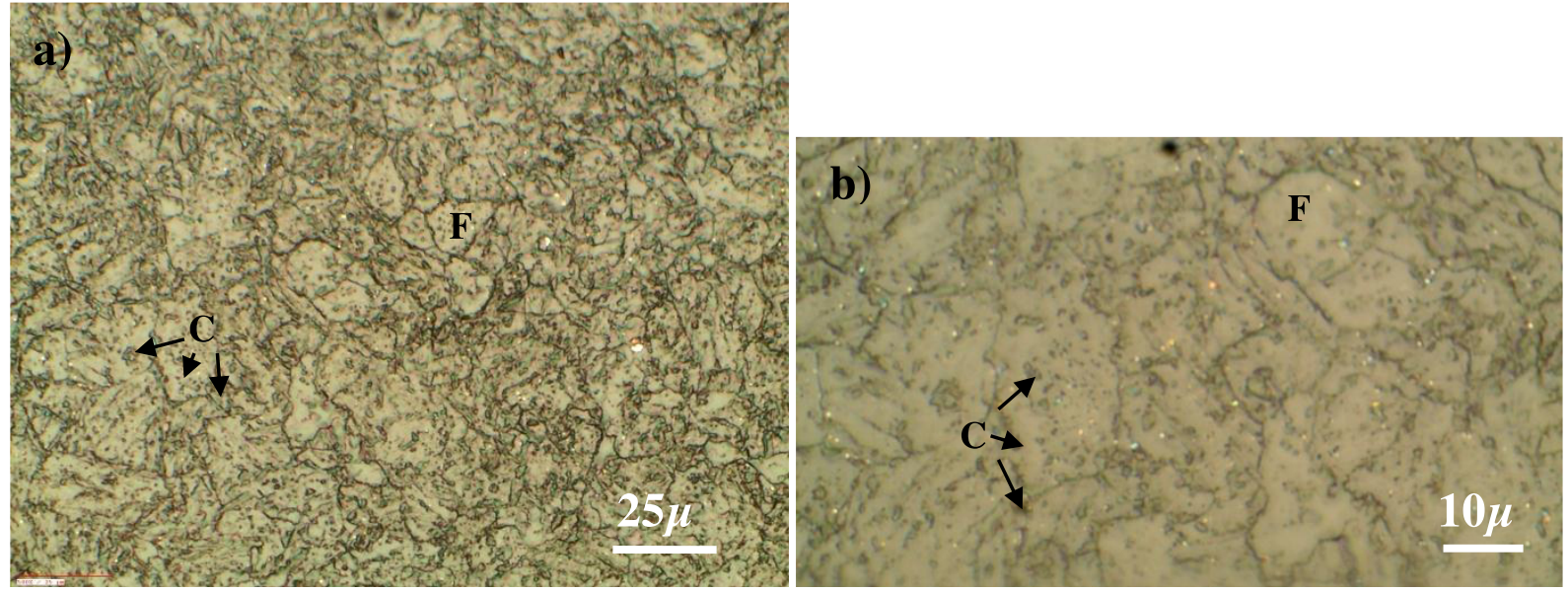

Fig. 9. a: Base metal area at lower magnification and; b: base metal area at higher magnification of pass I tube, F-ferrite grain structure and C-alloy carbides. 
Table 3. Chemical composition measured by XRF Positive material identification.

\begin{tabular}{lll}
\hline Chemical composition (\%) & Pass I tube & Pass II tube \\
\hline Silicon & $0.60 \pm 0.02$ & $0.58 \pm 0.01$ \\
Manganese & $0.44 \pm 0.02$ & $0.43 \pm 0.02$ \\
Chromium & $9.08 \pm 0.03$ & $9.10 \pm 0.02$ \\
Molybdenum & $1.05 \pm 0.01$ & $1.08 \pm 0.01$ \\
\hline
\end{tabular}

Table 4. Average grain size in various zone of heater tube.

\begin{tabular}{lcc}
\hline Zone area & $\begin{array}{l}\text { Average grain size } \\
\text { in } \mu \text { of Pass I }\end{array}$ & $\begin{array}{l}\text { Average grain size } \\
\text { in } \mu \text { of Pass II }\end{array}$ \\
\hline Weld metal & 7.7549 & 7.7498 \\
Heat affected zone & 18.214 & 18.1167 \\
Base metal & 16.412 & 16.3952 \\
\hline
\end{tabular}
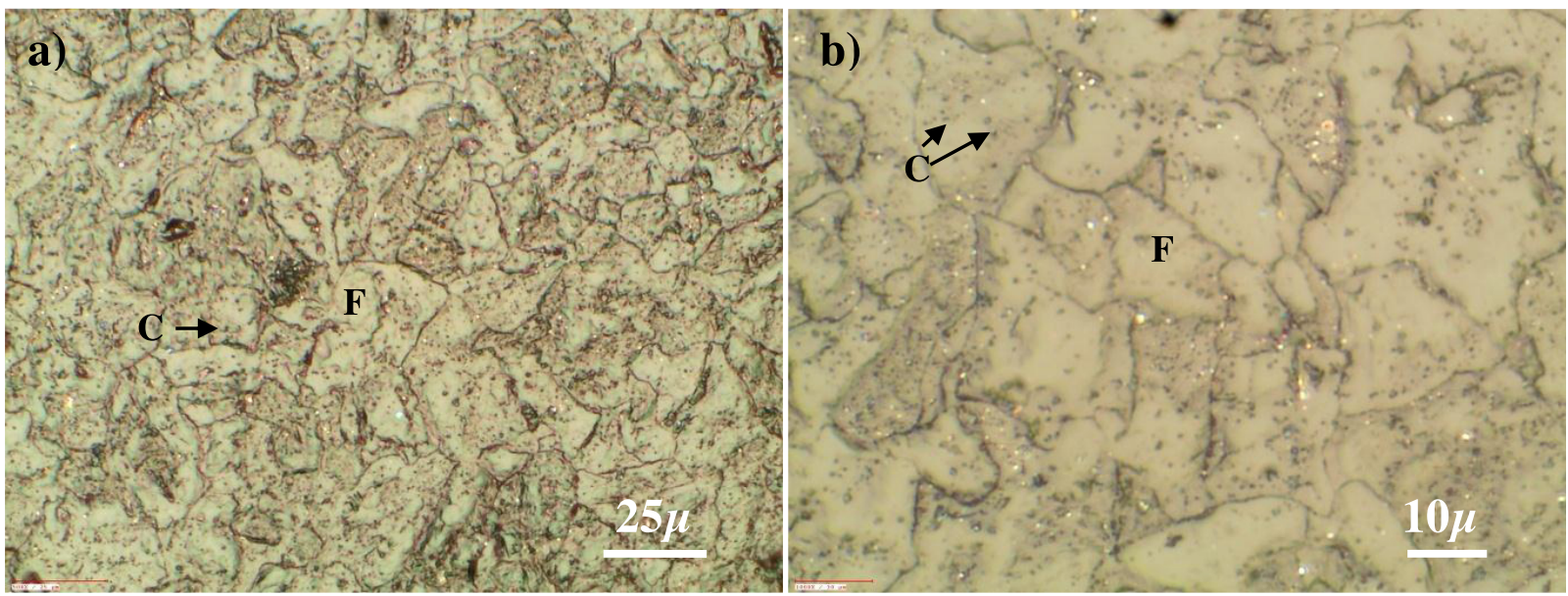

Fig. 10. a: Base metal area at lower magnification and; b: base metal area at higher magnification of pass II tube, F-ferrite grain structure and C-alloy carbides.

cellular dendritic tempered martensite structure. The microstructure in heat affected zone reveals blocky tempered martensite grain structure. The base metal microstructure contains coarse ferrite grains along with fine dispersed alloy carbides, and further reveals an absence of tempered martensite.

The heater tube weldment contains martensitic phase structure in as welded condition. Tempered martensite was observed in weld metal and HAZ clearly proves that weld joint was subjected to post weld heat treatment during heater tube construction to convert hard martensite obtained from welding into tempered martensite intended for high temperature services. Similar results were observed by other researchers $[8,9,14,15]$. These heater tubes are designed for $100000 \mathrm{~h}$, i.e., creep up to secondary creep regime. If tubes were operated beyond $100000 \mathrm{~h}$, the microstructure may show grain growth and cavity formation resulting in crack nucleation which leads to rupture of tubes which was shown by Viswanathan R [10]. The photomicrographs (refer Figs. 5-10) proves absence of slip planes, grain growth, cavity formation and crack. It is observed that there is no evidence of sub grain formation or grain boundary sliding along grain boundaries in microstructure. So far many researchers $[6,8-11]$ have reported that heater tubes operated beyond $650^{\circ} \mathrm{C}$ resulted in grain boundary sliding and intergranular crack for ASTM A213 GrT9 steels. Since the aforementioned tubes were exposed for less than $100000 \mathrm{~h}$, no defects were observed and it proves that the heater tube weld section is not damaged by creep. Viswanathan [10] observed that grain boundary in weld fusion line and heat affected zone is the weakest region in T9 tubes, and creep initiates crack which propagates along these weak grain boundaries.

As no such creep indications were revealed, the heater tubes are safe to operate further under ideal operating conditions within design limit. The average grain size measured in various zones of heater tube microstructure is shown in Table 4. The grain size is not uniform and varies from weld centerline to base metal, and these obtained results found good agreement with other researchers $[14,15]$. The weld metal shows small cellular dendrite grain structure which was formed during solidification of weld metal. In contrast to the weld metal, heat affected zone located adjacent to weldment reveals large grain structure which might have formed due to weld thermal cycle. The base metal grain size lies in intermediate range and it was controlled during tube manufacturing process.

It is inferred from heat affected zone microstructure that there was no grain growth even after exposure at $615^{\circ} \mathrm{C}$ for $52000 \mathrm{~h}$. However, heat affected zone microstructure largely depends on welding heat input, tube thickness, cooling rate and post weld heat treatment during heater tube construction. The average grain size of weld section comprising weld metal, HAZ and base metal of both the passes are similar. However, pass I tube grain size is relatively higher than pass II tube. During start up and shut down of furnace tube heater, a uniform heating rate and cooling rate of $50^{\circ} \mathrm{C}$ per hour was maintained. No sudden increase or decrease in furnace temperature was observed during intermediate plant outrage (if any) for last $52000 \mathrm{~h}$ of operation. 


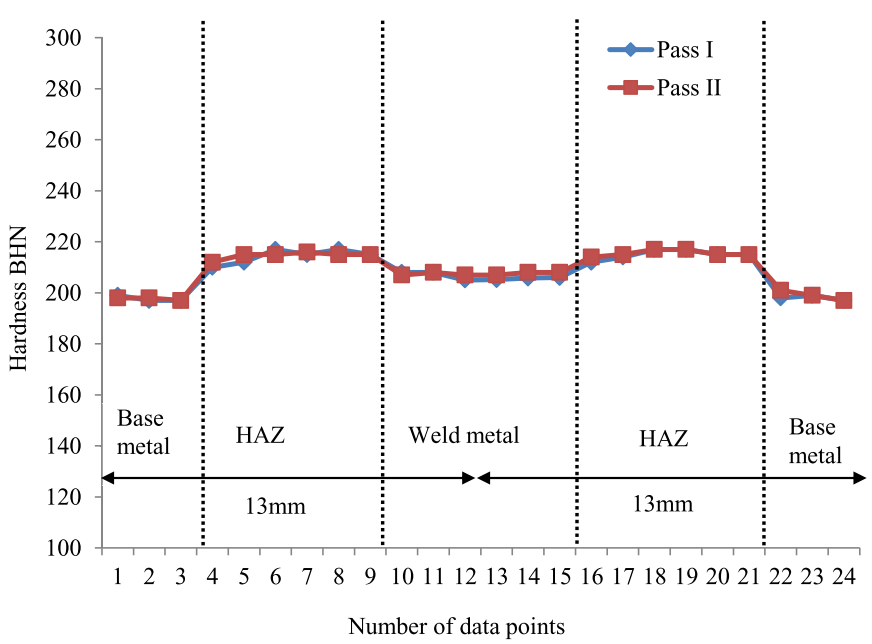

Fig. 11. Hardness of industrial tubes after an exposure of $52000 \mathrm{~h}$.

The coarse grain size increase the creep strength of metals and alloys, and creep strength increases with increase in grain size of metal. The hardness is measured on both the passes of heater tube (tube no.1 and tube no. 34) after replica preparation. The hardness is measured from heater tube replicated surface only for an in-situ metallography and it is plotted in Figure 11. Although slight variations were observed between both the tubes, heat affected zone shows slightly higher hardness value as compared to base metal and weld metal in both the tubes. Thus tempered martensite attributes to higher hardness in heat affected zone area. Heat affected zone area experienced various weld thermal cycle during heater tube construction welding favored initial formation of martensite.

Although preheating was done before welding, martensitic structure was formed in as-welded condition of heater tubes which was reported by other researchers $[2-5,11]$. Subsequently the heater tube weld joints were subjected to post weld heat treatment (refer Fig. 1 cycle) which resulted in formation of tempered martensite in both weld metal and heat affected zone area. Since base metal is fully annealed and weld metal is normalized and tempered, weld metal hardness is slightly higher than base metal as shown in Figure 11. The data points shown in Figure 11 are measured longitudinally covering three regions. Therefore $9 \mathrm{Cr}-1 \mathrm{Mo}$ steel heater tubes after an exposure of 5.9 years are not affected by creep damage in sense to industrial operation or in other words creep strain not yet reached to secondary creep regime.

\section{Discussions}

The heater tubes operating with known internal pressure and temperature are approximately predicted based on uni-axial creep data analysis. The maximum value of stress state variable is related to area fraction of cavitation damage. Qiang Xu et al. [16] show that the maximum value of stress state in uni-axial condition is $1 / 3$ of multi axial condition. Therefore, approximately stress state is 3 times higher than obtained strain (stress state). Appropriate strain $\left(11.2761 \times 10^{-2}\right.$ and $11.2802 \times 10^{-2}$ for respective temperatures 888 and $923 \mathrm{~K}$ ) conversion in to stress state will be less than maximum stress state variable resulting in no cavitation damage is correlated well with observed in microstructure.

In the base metal micrograph of both tubes shown in Figures 9 and 10, the white constituent is ferrite blocky structure and black constituents are alloy carbide present mostly within ferrite matrix. Alloy carbides $\mathrm{M}(\mathrm{C}, \mathrm{N})$ and $\mathrm{M}_{23} \mathrm{C}_{6}$ are finely dispersed in ferrite matrix influencing creep strength of base metal. It is well understood from the base metal microstructure that heater tube supplied for furnaces is supplied in annealed condition and no martensitic structure was observed according to ASME BPV codes and standards [1]. The alloy carbides size and its distribution greatly enhance the creep strength in base metal. However, weld metal and heat affected zone of both tubes (refer Figs. 5-8) micrographs shows presence of blocky tempered martensite and this tempered martensitic structure enhances the creep strength.

Alloy carbides were not observed in both weld metal and HAZ area which further indicates no carbide precipitation was formed during last $52000 \mathrm{~h}$ of exposure. This finding agrees with results of other researchers $[4-6,8,11]$. Also it is very well understood that alloy carbides does not play any role in enhancing creep strength of weld metal and heat affected zone area. The weld metal is directionally solidified (refer Figs. 5 and 6) as columnar structure in weldment. The microstructure of base metal, HAZ and weld metal of pass I tube no. 1 and pass II tube no. 34 were found identical which further confirmed that there was no deviation during last $52000 \mathrm{~h}$ of heater tube operation.

\section{Conclusion}

From operational creep strain estimation and in-situ metallography studies, it has been concluded that heater tubes are free from creep damage and no cracks were obtained. The maximum creep strain are found in primary creep regime with creep strain $(\varepsilon)=11.2761 \times 10^{-2}$ and $(\varepsilon)=11.2802 \times 10^{-2}$ for temperature 888 and $923 \mathrm{~K}$, respectively. Also, the strain estimation shows that the heater tubes might be designed against stress to accommodate $2 \%$ per $10000 \mathrm{~h}$ or $5.5 \times 10^{-9} \mathrm{~s}^{-1}$ as an approximate creep strain rate for hydrocarbon processed ASTM A 213 Grade T9 heater tubes. The heater tubes made of T9 grade chromium molybdenum steels are highly resistant to high temperature damages up to $615^{\circ} \mathrm{C}$ and are quite successful for vacuum residue coker furnace operation.

\section{Recommendations}

It is further recommended to evaluate heater tubes:

- for newly constructed furnace, initial grain size of heater tubes shall be recorded before start of operations;

- experimental investigations of in-situ metallography shall be conducted at every opportunities of turnaround. Further, compare latest average grain size with initial average grain size to measure quantitative creep growth; 
- stress rupture tests or accelerated creep tests shall be carried out for heater tubes of radiation zone to estimate remaining life;

- detailed metallography investigations shall be carried out at surface (fire side), mid wall thickness and inner surface (vacuum residue side) to evaluate internal carburization or any other damages;

- for re-rating of heater tubes from $615^{\circ} \mathrm{C}$ to higher temperatures within $640^{\circ} \mathrm{C}$ or to lower temperature within $600^{\circ} \mathrm{C}$, stress rupture tests shall be carried out at an appropriate re-rated operating temperature.

\section{Future scope of work}

- The limitation and uncertainty for predicting creep strain by current approach are:

- actual heater tubes shall be three dimensional modeled but in current study, the prediction of creep strain was obtained using uni-axial modified power law;

- the creep failure is highly localized and expressing all physical significance of material creep behavior (dislocation climb, recovery, re-crystallization, and grain growth) into mathematical form is complex which leads to certain uncertainties while predicting creep strain and creep rate.

- Keeping in view of above limitations and uncertainties, the heater tube shall be modeled to address specific high temperature industrial atmospheres;

- The parent base metal and weld shall be predicted and characterized for three dimensional creep analyses and further correlation shall be established with uni-axial material behavior.

\section{References}

1. ASME, ASME boiler and pressure vessel code rules for construction of pressure vessel section IIA, ASME, New York, 2015, pp. 313-326

2. C.C. Chen, A. Pollack, Influence of welding on steel weldment properties, Am. Soc. Metals 06, 416-428 (1993)
3. D.S. Donald, F.W. Kern, Steel tubular products, Am. Soc. Metals 09, 210-216 (1998);

4. R.W. Swindeman, M. Gold, Developments in ferrous alloy technology for high temperature service, J. Pressure Vessel Technol. 113, 113-140 (1991)

5. R.W. Swindeman, W. Ren, Fatigue and fracture resistance of heat resistant (Cr-Mo) ferritic steels, Am. Soc. Metals 19, 704-711 (1993)

6. V.K. Sikka, et al., Modified 9Cr-1Mo steel-An improved alloy for steam generator applications, Ferritic steels for high temperature applications, Am. Soc. Metals, 65-84 (1983)

7. F. Kafexhiu, F. Vodopivec, B. Podgornik, Analysis of primary creep in simulated heat affected zone (HAZ) of two 9-12\% Cr steel grades, Metalurgija 56, 353-356 (2017)

8. H.H. Matsumoto, et al., Development of $9 \mathrm{Cr}-0.5 \mathrm{Mo}-1.8 \mathrm{~W}$ steel for boiler tubes First international conference on improved coal-fired power plants, Eur. Power Res. Institute, 5.203-S.218 (1986)

9. S. Atanu, H. Roy, Failure investigation of secondary super heater tube in a 140-MW thermal power plant, Case Stud. Eng. Failure Anal. 8, 57-60 (2017)

10. R. Viswanathan, Damage mechanisms and life assessment of high temperature components, Metals Park: ASM International, 1989

11. F. Masuyama, et al., Development of tungsten strengthened low alloy steel with improved weldability, service experience and reliability improvement: nuclear, fossil and petrochemical plants, ASME Pressure Vessel Piping 288, 141-146 (1994)

12. ASTM, Standard practice for production and evaluation of field metallographic replicas ASTM E1351-01, ASTM, New York, 2012, pp. 970-975

13. 2007 ASTM, Standard practice for micro etching metals and alloys ASTM E407-07, ASTM, New York, pp. 554-573

14. A. Saha, A.K. Shukla, Failure of a secondary super heater tube in a $140-\mathrm{MW}$ thermal power plant. J. Failure Anal. Prevent 14, 10-12 (2014)

15. A. Saha, H. Roy, A.K. Shukla, Failure of a final super heater tube in a 140-MW thermal power plant, J. Failure Anal. Prevent 15, 184-189 (2015)

16. Q. Xu, Z. Lu, X. Wang, Damage modelling: the current state and the latest progress on the development of creep damage constitutive equations for high Cr steels, Mater. High Temp. 34, 229-237 (2017)

Cite this article as: Chidambaram Subramanian, Experimental in-situ metallographic investigations of industrial hydrocarbon processed fired heater tubes, Metall. Res. Technol. 116, 203 (2019) 